\title{
Caso radiológico de desafío diagnóstico
}

\section{Dres. Gonzalo Corral $G^{(1)}$, Andrés Sanhueza $Z^{(2)}$, Luis Tapia ${ }^{(3)}$, Emilio Muse $\boldsymbol{R}^{(4)}$.}

1. Radiólogo. Clínica Dávila. Hospital Dr. Exequiel González Cortés. Santiago, Chile.

2. Residente de Radiología. Universidad de los Andes. Santiago, Chile.

3. Residente de Radiología. Pontificia Universidad Católica de Chile. Santiago, Chile.

4. Radiólogo. Unidad de Radiología Osteomuscular, Clínica Dávila. Santiago, Chile.

\section{Historia clínica}

Paciente de 14 años, sexo masculino, sin antecedentes mórbidos.

Consulta en urgencias por cuadro de omalgia derecha intermitente de siete días de evolución asociado a rigidez y dolor cervical. En los tres últimos días se agrega tope inspiratorio y sensación febril intermitente. Se solicita una radiografía de tórax PA-L (Figuras 1 y 2 ).

\section{¿Cuál es su diagnóstico?}
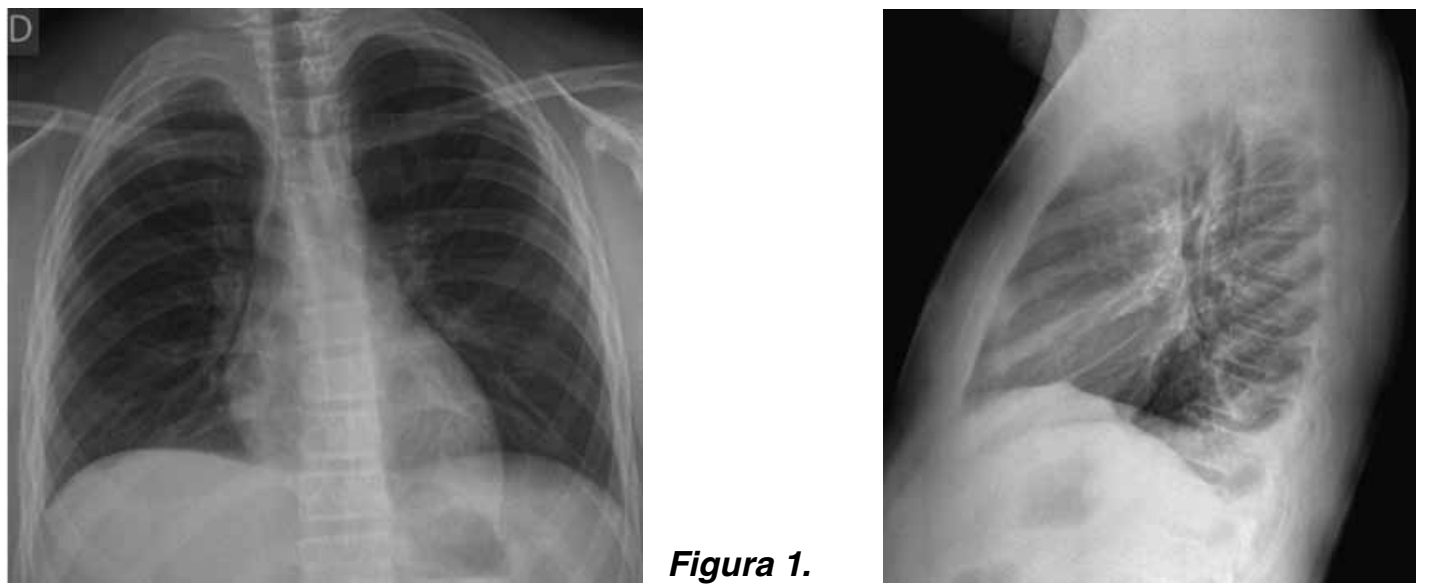

Figura 2.

Dado el cuadro clínico y los hallazgos en la radiografía, se decide realizar un tomografía computada (TC) de tórax (Figuras 3, 4 y 5) y cuello (Figuras 6 y 7 ).

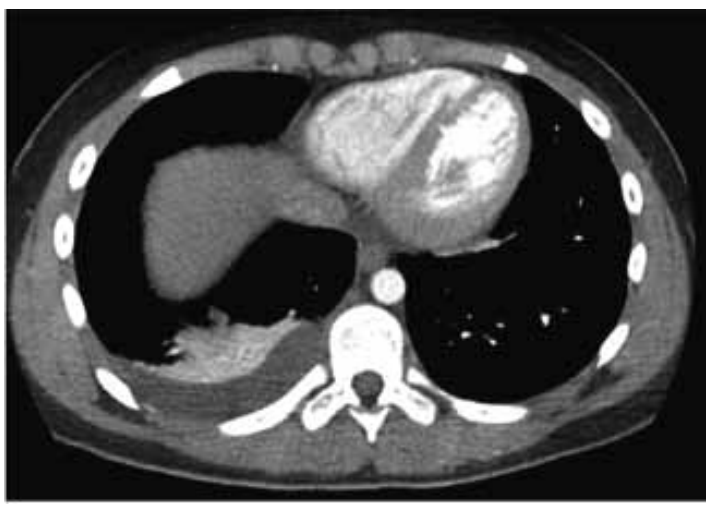

Figura 3.

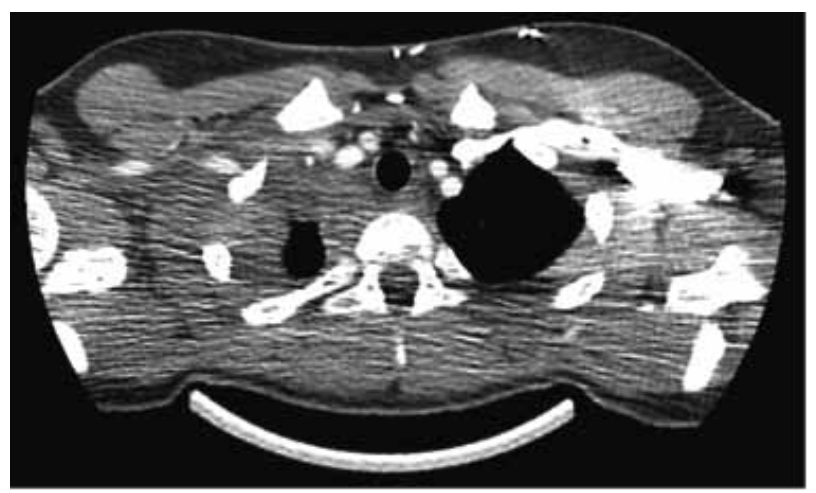

Figura 4. 


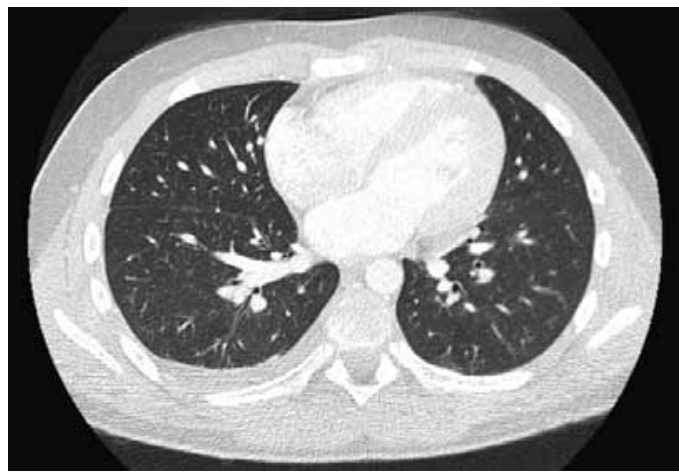

Figura 5.

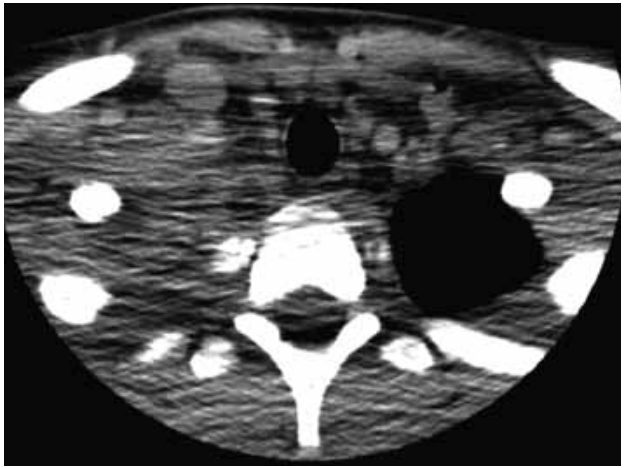

Figura 6.

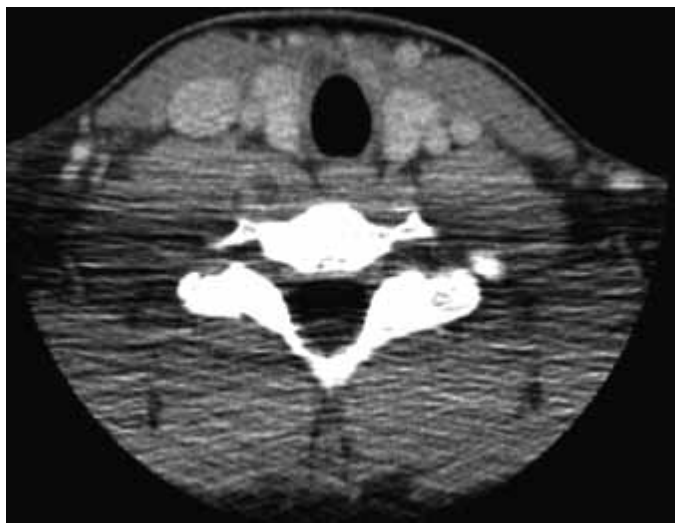

Figura 7.

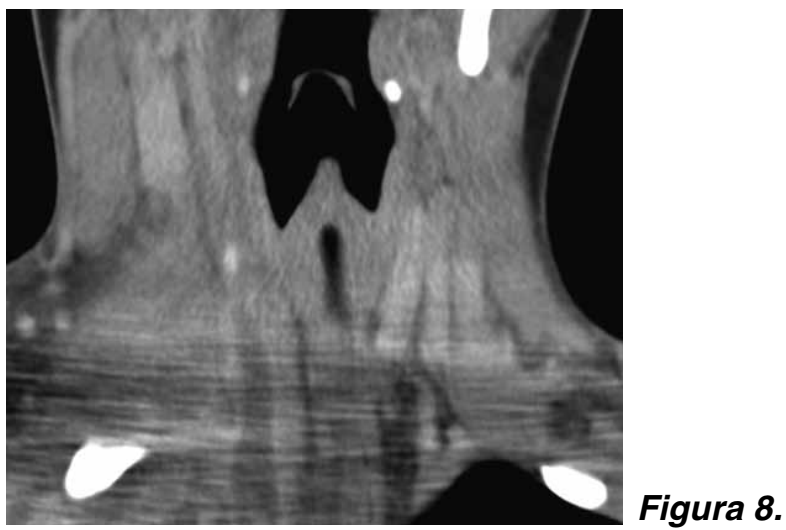

Reconstrucción coronal oblicua en el eje de musculatura prevertebral (Figura 8). TC de cuello en ventana ósea (Figura 9) y reconstrucción sagital (Figura 10).

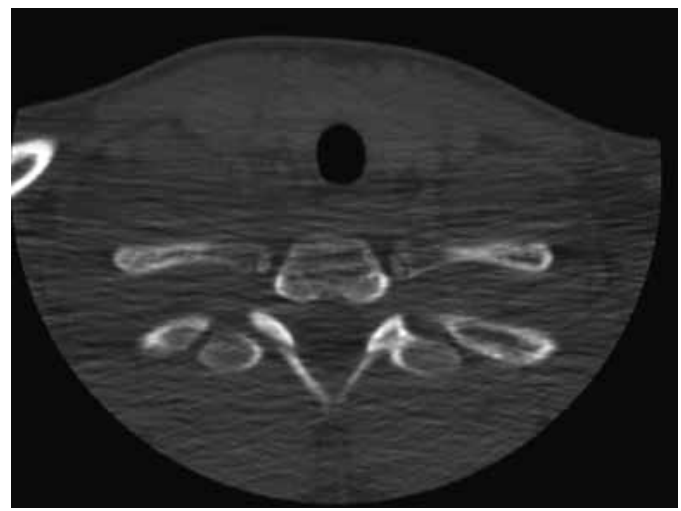

Figura 9.

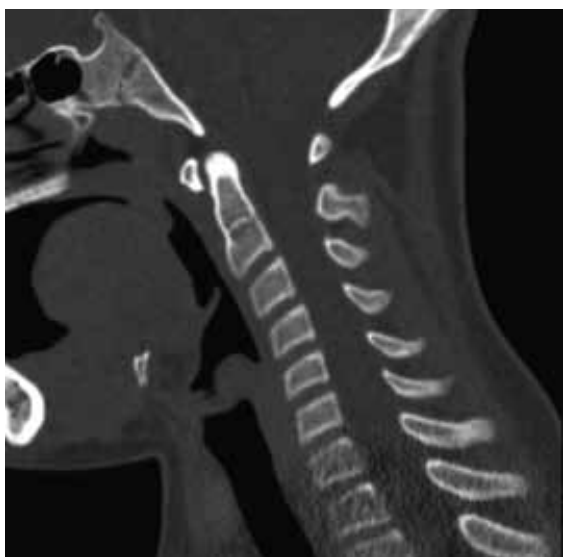

Figura 10.

El paciente se hospitaliza y se solicita una resonancia magnética (RM) de cuello para mejor caracterización. Secuencia STIR. Cortes axial (Figura 11), sagital (Figura 12) y coronal (Figura 13), Secuencia HASTE, corte axial (Figura 14).

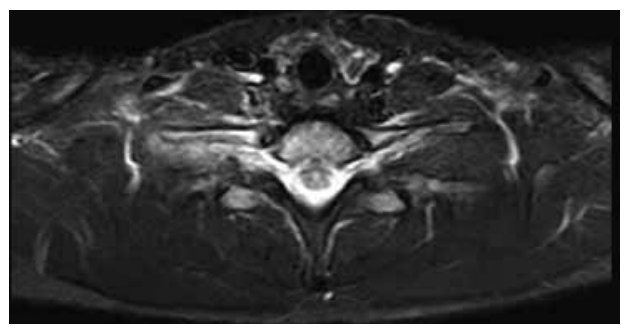

Figura 11.

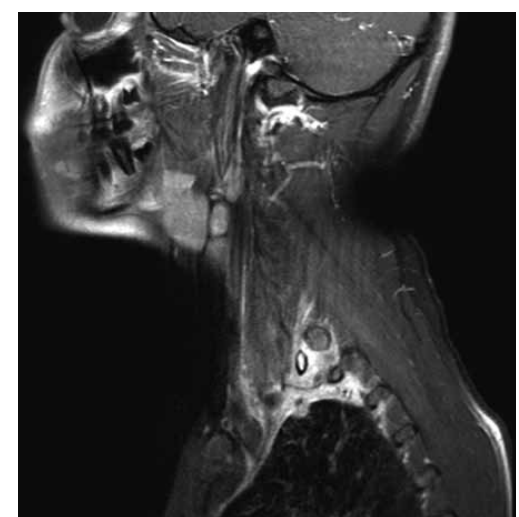

Figura 12. 

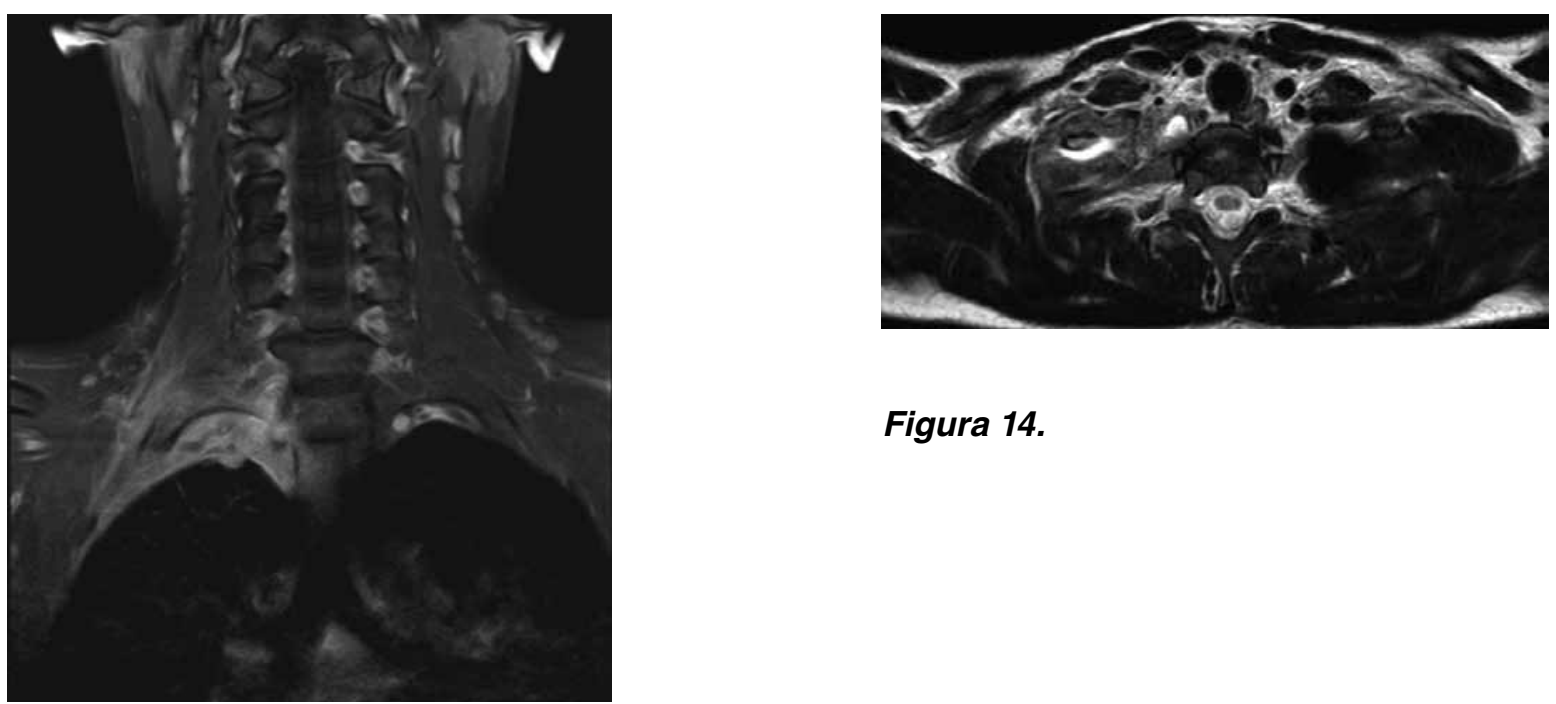

Figura 14.

\section{Figura 13.}

Secuencia T1-eco de gradiente con saturación grasa y contraste (T1 GRE ft-sat c+), cortes axiales (Figuras 15 y 16).

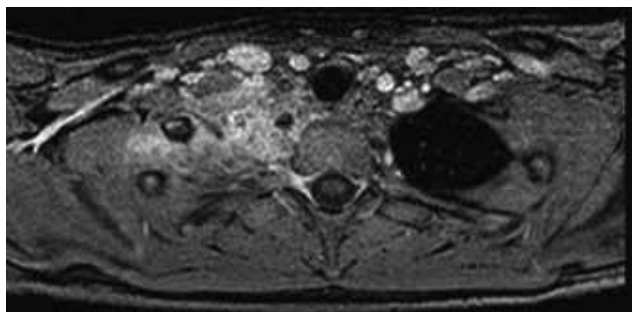

Figura 15.

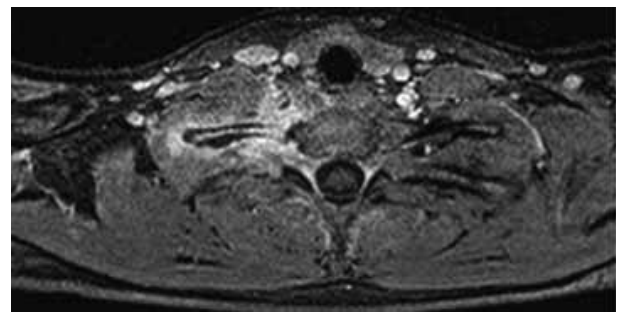

Figura 16.

Secuencia STIR, corte coronal (Figura 17) y T1 GRE fat sat c+, corte coronal (Figura 18). Durante la hospitalización se obtiene un hemocultivo a positivo para Staphylococcus.

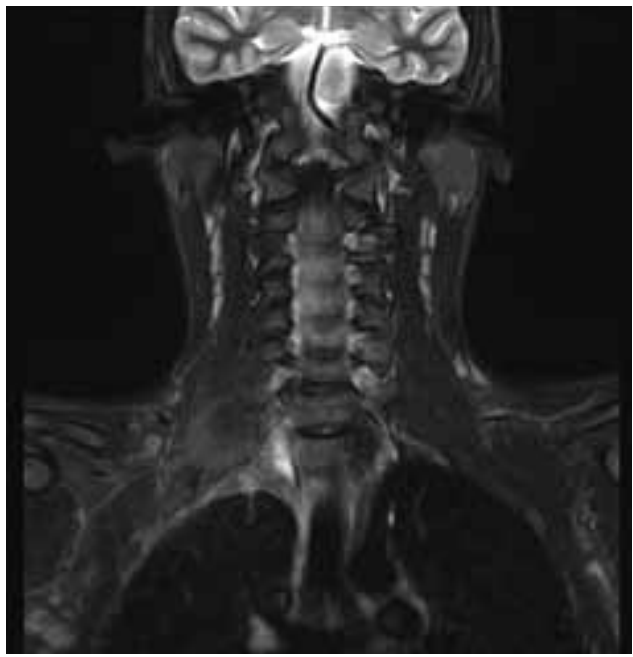

Figura 17.

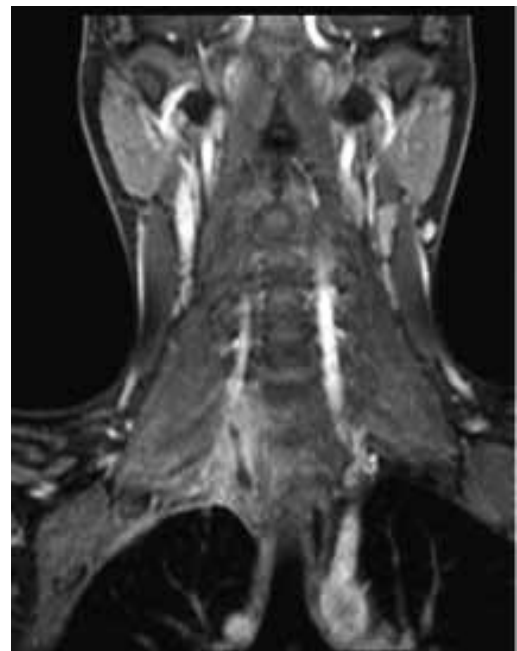

Figura 18. 


\section{Resultado caso radiológico de desafío diagnóstico}

Dres. Gonzalo Corral $G^{(1)}$, Andrés Sanhueza $Z^{(2)}$, Luis Tapia $C^{(3)}$, Emilio Muse $R^{(4)}$.

1. Radiólogo. Clínica Dávila. Hospital Dr. Exequiel González Cortés. Santiago, Chile.

2. Residente de Radiología. Universidad de los Andes. Santiago, Chile.

3. Residente de Radiología. Pontificia Universidad Católica de Chile. Santiago, Chile.

4. Radiólogo. Unidad de Radiología Osteomuscular, Clínica Dávila. Santiago, Chile.

viene de la página 91.

\section{Diagnóstico}

Osteomielitis aguda de la primera costilla derecha y piomiositis del músculo largo del cuello derecho. Engrosamiento y derrame pleural ipsilateral secundario.

\section{Discusión \\ Generalidades}

La osteomielitis es una patología que en la mayoría de los casos es debida a una infección bacteriana. En pediatría puede ocurrir a cualquier edad, sin embargo, es más frecuente en niños entre 2 - 12 años. La incidencia es de aproximadamente $1 / 5.000$ en pacientes pediátricos, siendo los de sexo masculino afectados en una relación 2:1 respecto a las de sexo femenino ${ }^{(1-3)}$.

En niños la vía de infección hematógena es la más común. Otras vías son por contigüidad y siembra directa, como por ejemplo, en casos de trauma expuesto ${ }^{(4,5)}$.

La osteomielitis costal representa menos del $1 \%$ de los casos y su diagnóstico puede retrasarse debido a síntomas inespecíficos e intermitentes ${ }^{(6)}$.
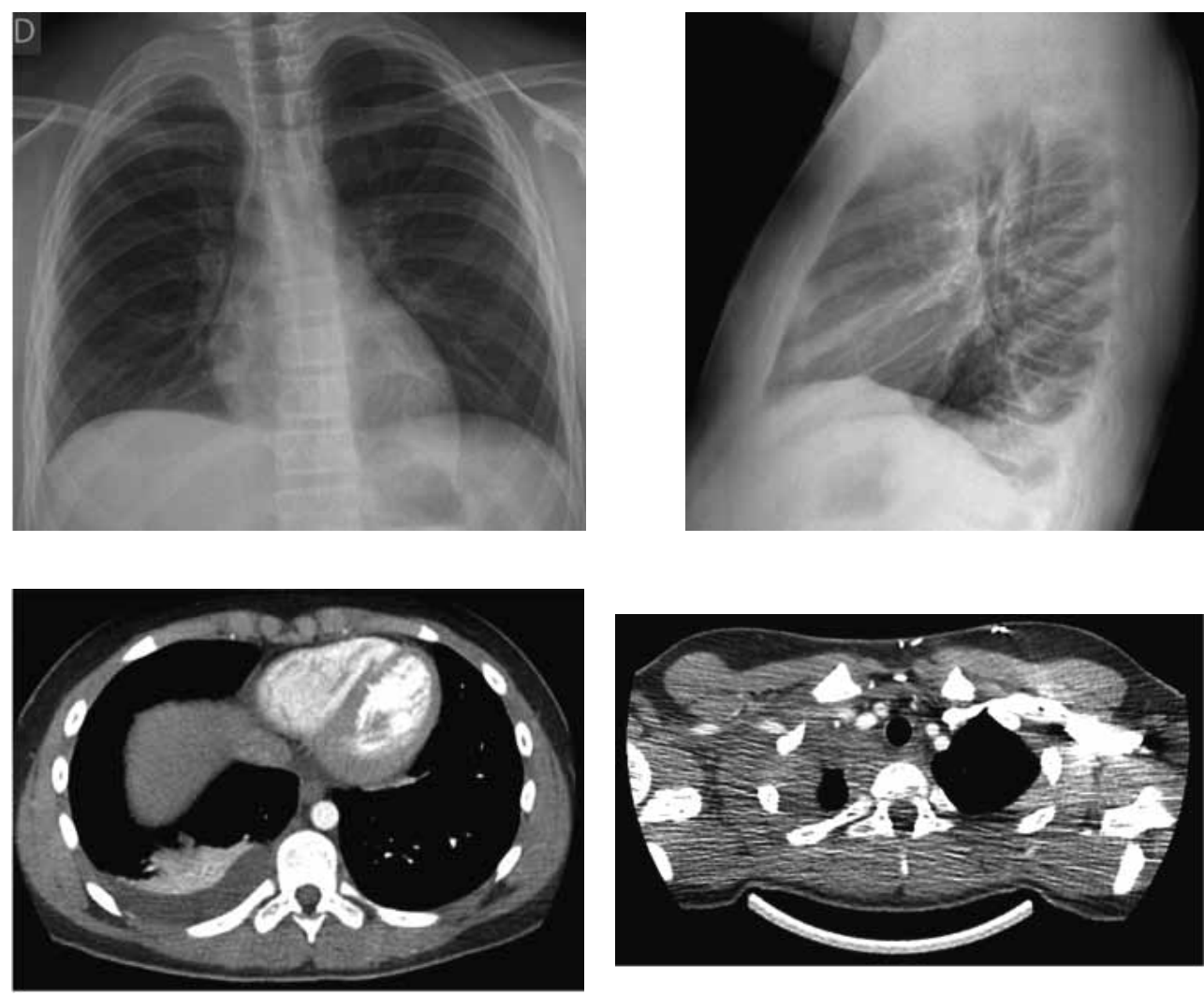

Figuras 1 y 2. Radiografía de tórax AP-L. Leve derrame pleural derecho e imagen apical derecha sugerente de engrosamiento pleural.
Figuras 3 y 4. Cortes axiales de TC de tórax con ventana de partes blandas. Confirman el leve derrame pleural derecho y engrosamiento pleural apical ipsilateral. 
Respecto a la miositis infecciosa, es una patología poco frecuente la cual puede ser causa o consecuencia de una osteomielitis. Se denomina piomiositis cuando su etiología es bacteriana, siendo el agente más común Staphylococcus aureus ${ }^{(7)}$. En el caso expuesto, se manifestó como una colección inflamatoria en el espesor del músculo largo del cuello (Figuras 6, 7, 8, $11,17 a$ y 17b). Especial énfasis merece la anatomía de este músculo, que es parte del grupo de la musculatura prevertebral, donde también se encuentra el músculo largo de la cabeza y escalenos, entre otros. El Longus Colli, como también se denomina, se extiende desde el atlas hasta la tercera vértebra dorsal, presentando tres fascículos:

- Oblicuo superior: Desde el arco anterior del atlas a las apófisis transversas de las vértebras cervicales medias.

- Oblicuo inferior: Desde las apófisis transversas de las vértebras cervicales medias al aspecto anterior de las primeras vertebras dorsales.

- Vertical: Desde el aspecto anterior de las primeras vértebras cervicales al aspecto anterior de los primeros cuerpos vertebrales dorsales.

La piomiositis de este caso se centra en el fascículo oblicuo inferior, dando la disposición del absceso intramuscular (Figura 17c). También es interesante que de esta forma se explica el engrosamiento y derrame pleural ipsilateral, ya que probablemente este músculo, sumado al efecto directo de la osteomielitis costal, sirvió de "puente" entre el cuello y el tórax, determinando el engrosamiento y derrame pleural reactivos a la inflamación.

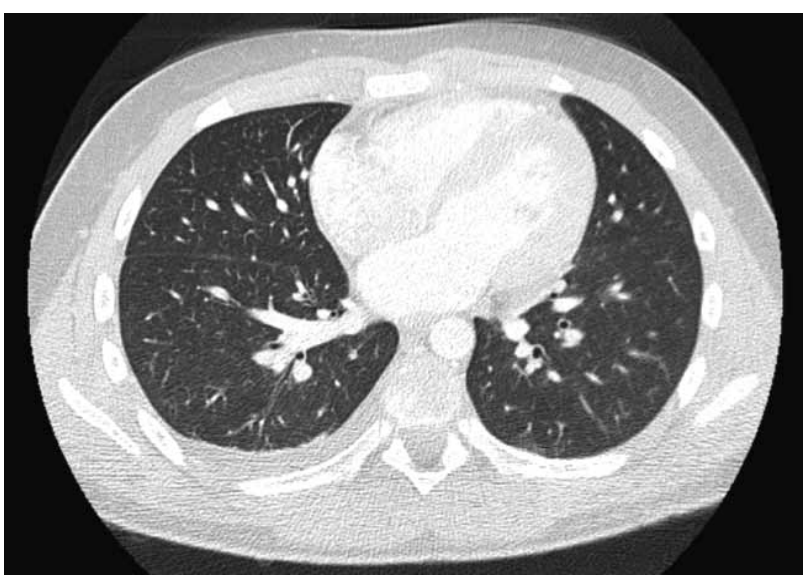

Figura 5. Corte axial de TC de tórax con ventana pulmonar. El parénquima pulmonar no presenta imágenes patológicas.

Figuras 8. Reconstrucción coronal oblicua en el eje de musculatura prevertebral. Lesión hipodensa, que se extiende a través de la musculatura prevertebral derecha.
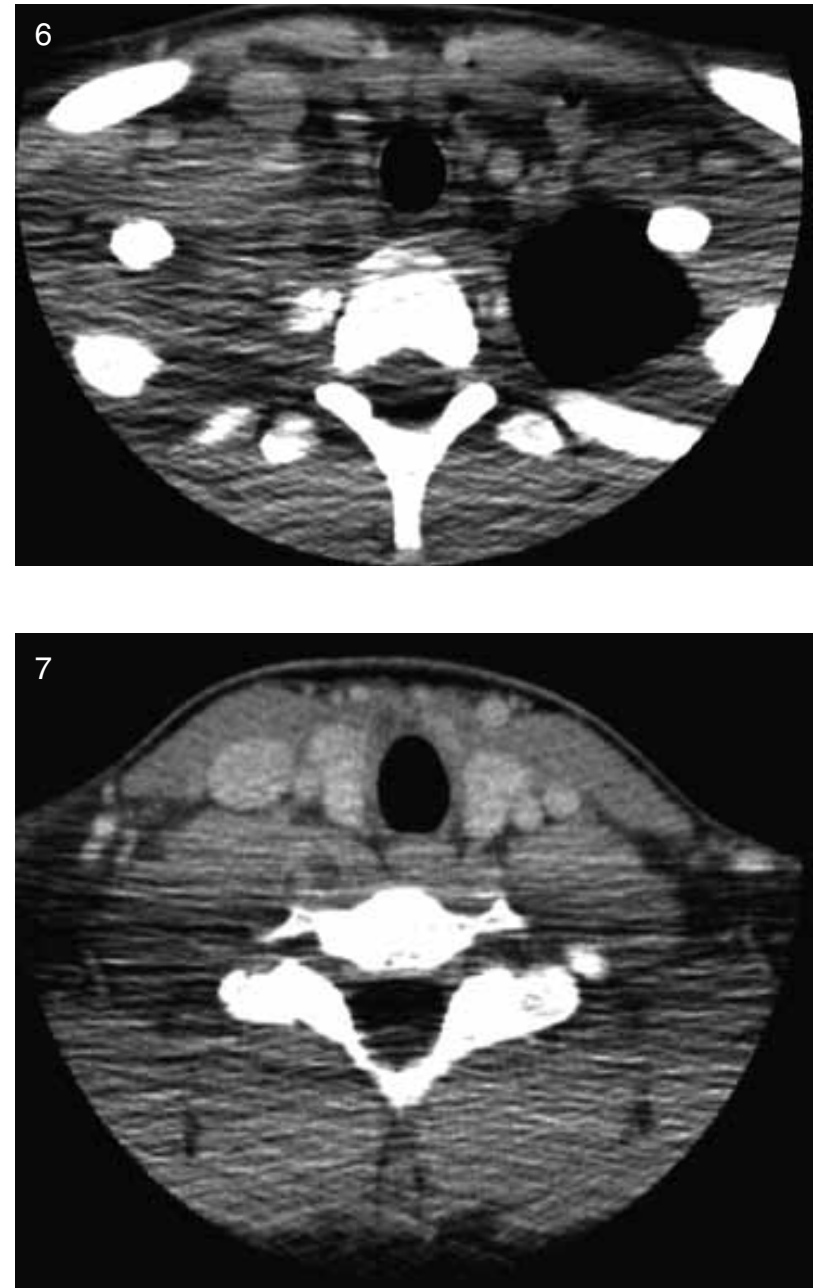

Figuras 6 y 7. TC de cuello en ventana de partes blandas. Imagen hipodensa redondeada que realza en forma periférica con el medio de contraste en el espesor de la musculatura prevertebral, en situación parasagital derecha.

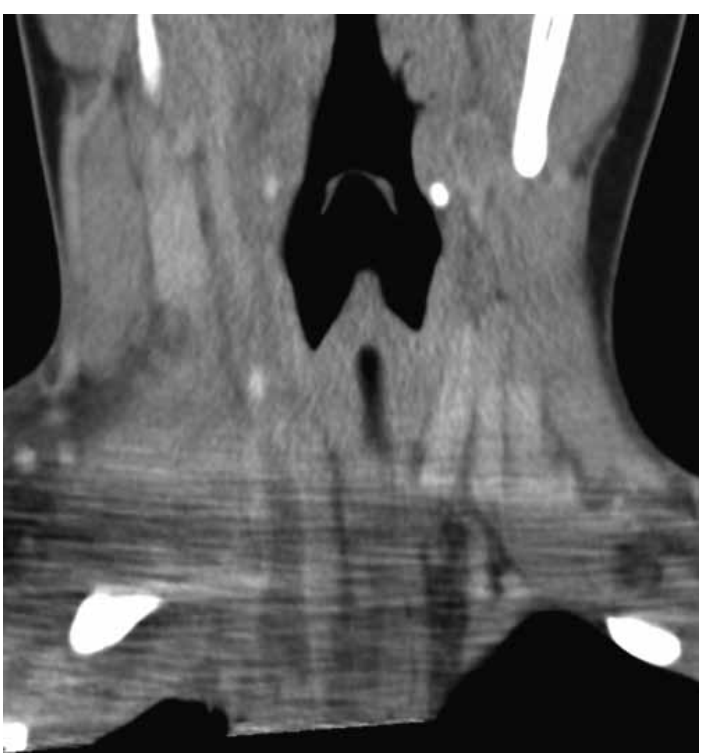



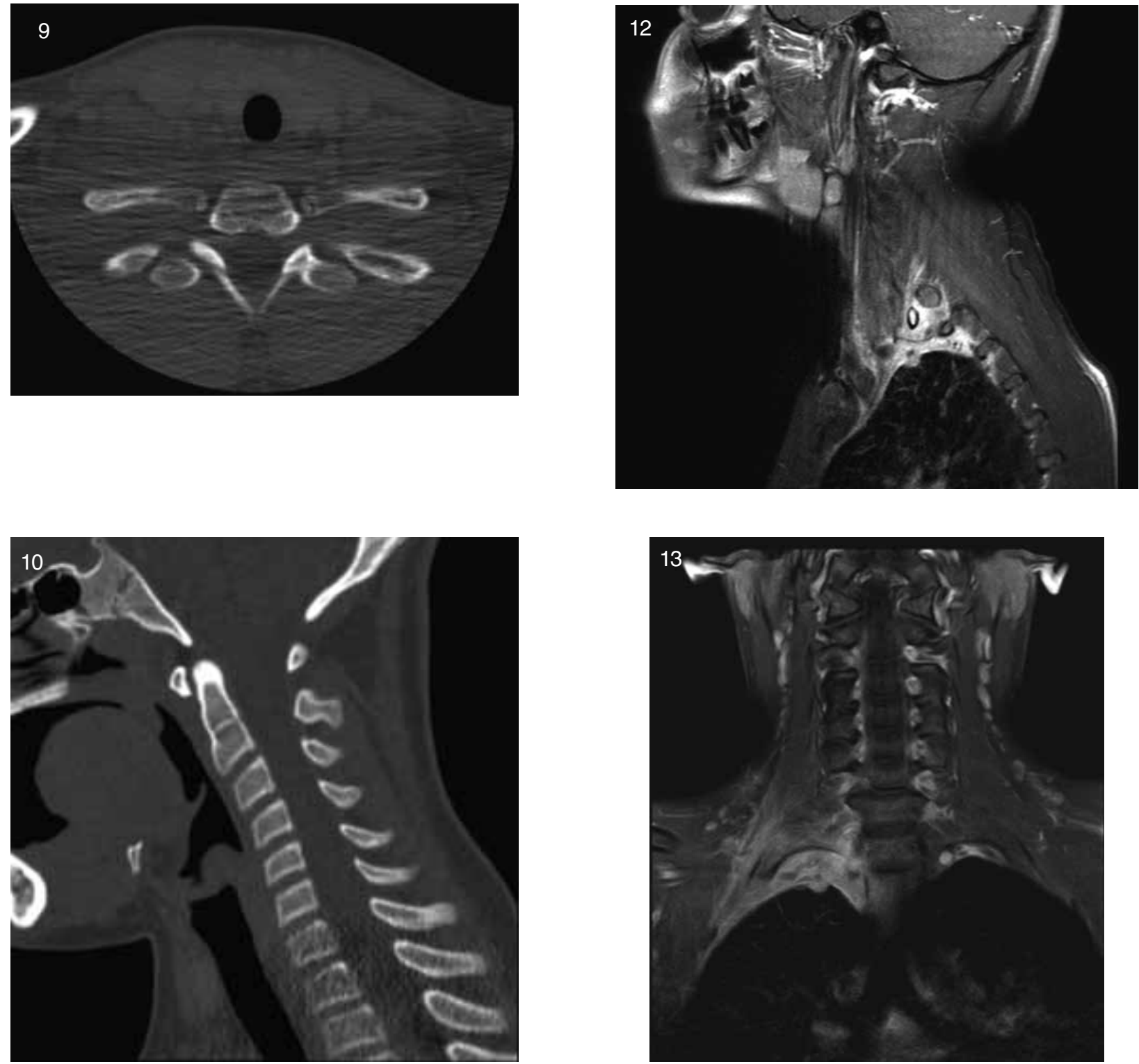

Figuras 9 y 10. Corte axial y reconstrucción sagital de TC de cuello en ventana ósea. Estructura ósea normal, sin hallazgos patológicos.

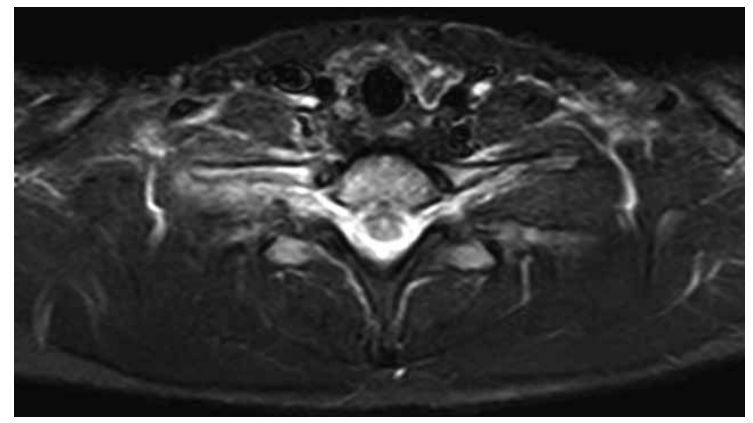

Figura 11. Secuencia STIR, corte axial.

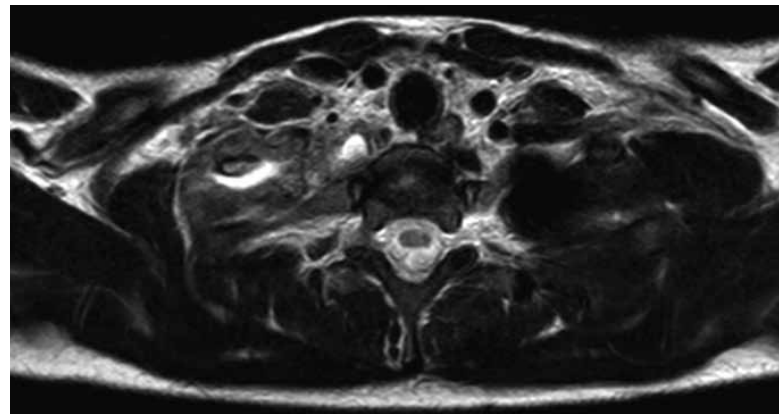

Figura 14. Secuencia HASTE, corte axial. Se confirma una lesión de alta señal en el espesor del músculo largo del cuello derecho, sugerente de una colección. 

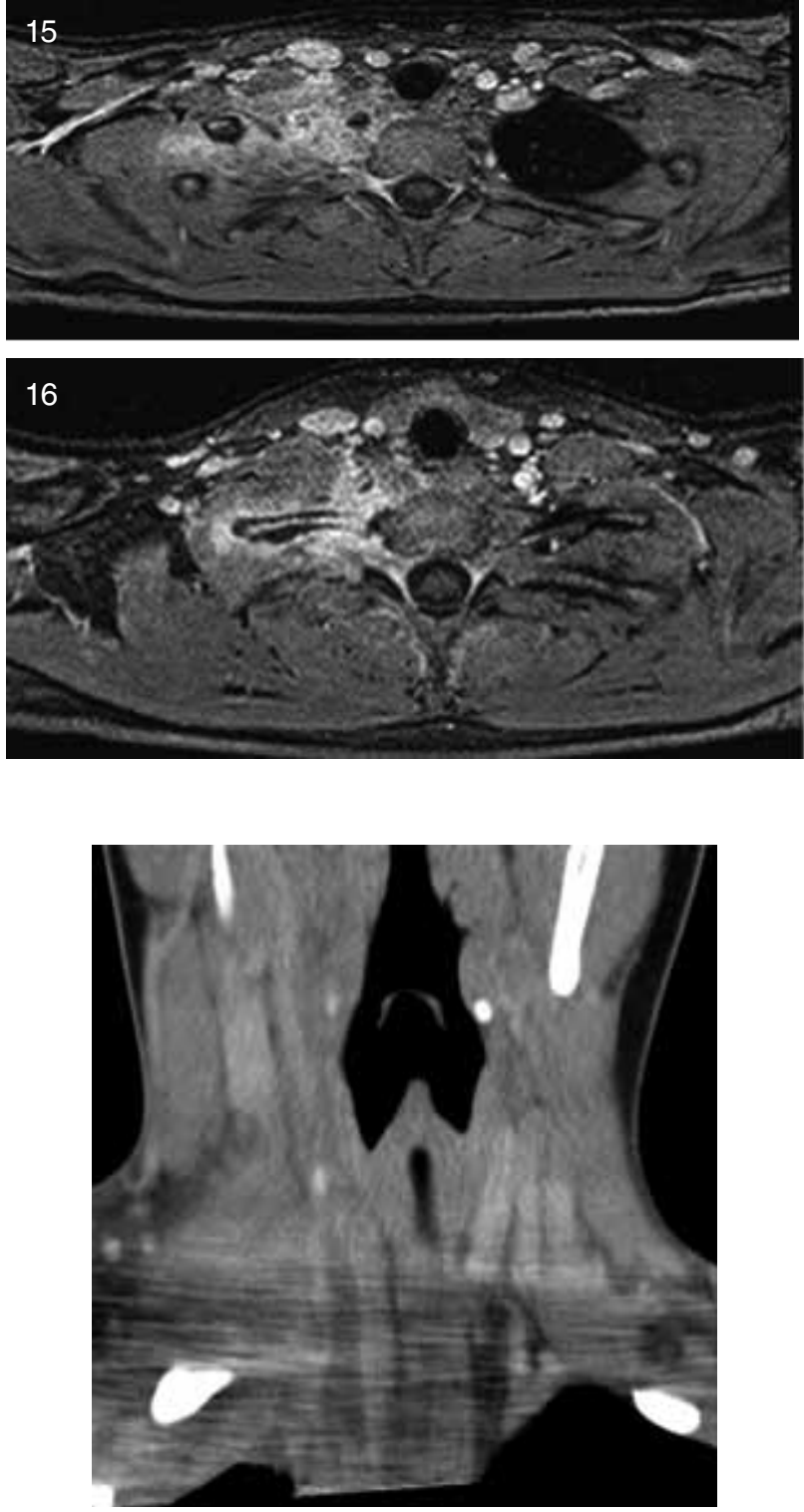

Figuras 17a.

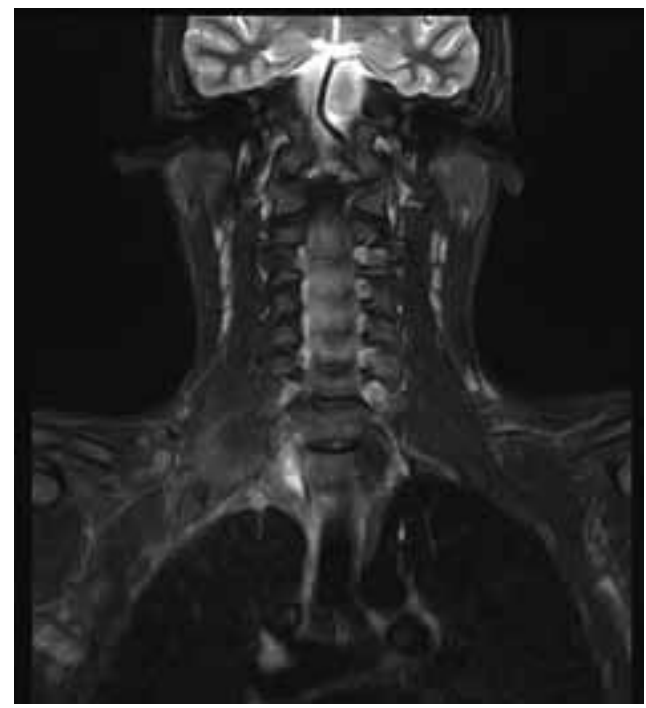

Figuras 17b.
Figuras 15 y 16. Secuencia T1 GRE fat-sat c+, cortes axiales. Se observa refuerzo con el medio de contraste de las partes blandas adyacentes a la primera costilla y de forma periférica en anillo a colección inflamatoria en el espesor del músculo largo del cuello derecho.
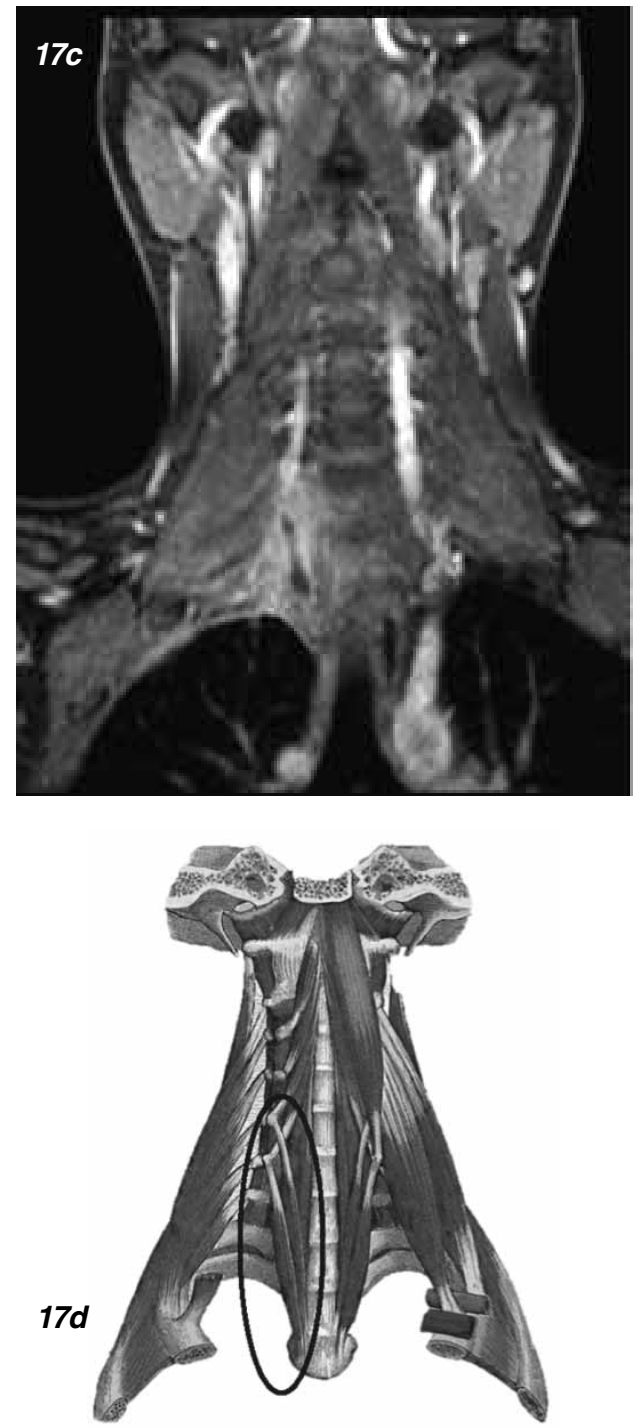

Figuras $17 \boldsymbol{a}, \boldsymbol{b}, \boldsymbol{c}, \boldsymbol{d}$. Reconstrucción de TC, coronal oblicua en el eje de musculatura prevertebral (a), secuencia STIR, corte coronal (b), secuencia T1 GRE fat-sat c+, corte coronal (c) e ilustración anatómica de la musculatura prevertebral (d), el círculo azul indica al fascículo oblicuo inferior izquierdo. Se puede apreciar la disposición de piomiositis del músculo largo de cuello derecho, probablemente en su fascículo oblicuo inferior.

\section{Osteomielitis en niños: Consideraciones anatómicas}

Como se mencionó anteriormente, en pediatría la forma más frecuente de etiopatogenia es hematógena, y para comprender la localización de la infección se deben considerar algunas diferencias anatómicas dependiendo la edad.

Recién nacido (RN): los vasos nutricios penetran directamente hasta la epífisis, dado que aún no se cons 
tituye la barrera fisiaria (Figura 18). Son infecciones con graves consecuencias si no se tratan precozmente, ya que se relacionan hasta en un $80 \%$ con artritis séptica, con una rápida destrucción de la articulación, especialmente en $\mathrm{RN}$ de pre-término ${ }^{(8,9)}$.

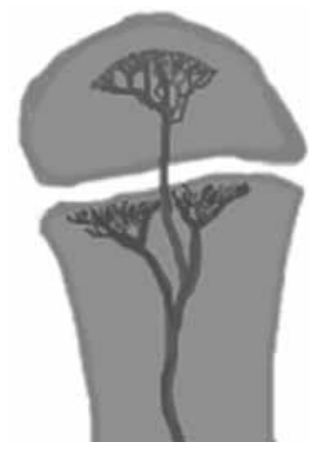

Figuras 18. Irrigación de epífisis en RN.

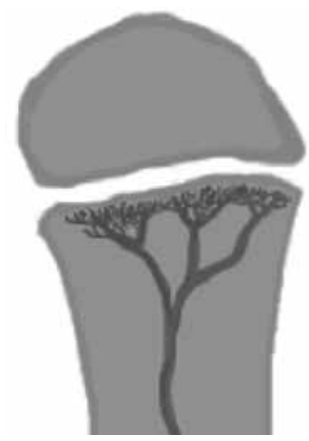

Figuras 19. Irrigación metafisiaria en preescolares $y$ escolares.

Pre-escolar, escolar: a los 18 meses se constituye la barrera fisiaria, por lo que desde esta etapa se presenta la osteomielitis metafisiaria, localización más frecuente del global de osteomielitis en pediatría. Esto se explica, ya que lo vasos nutricios llegan a la metáfisis formando "lagos vasculares" de flujo lento donde se alojan las bacterias (Figura 19). Se debe tener en cuenta que las metáfisis proximales del fémur, húmero y radio son intraarticulares, con el consecuente de mayor riesgo de artritis séptica. Por otra parte, existen "equivalentes metafisiarios" que tienen el mismo riesgo que las metáfisis de desarrollar esta enfermedad. Este grupo lo componen partes del esqueleto adyacentes a cartílago o núcleos de osificación secundarios como el trocánter mayor, calcáneo y vértebras; también los huesos planos como la pelvis y escápula ${ }^{(8,9)}$.

Adulto: aunque no es objetivo de este trabajo, cabe mencionar que en el esqueleto maduro, dado que la fisis se cierra, se restablece el flujo vascular hacia la epífisis. Cuando la infección se establece vía hematógena (poco frecuente), se produce una afección subcondral con riesgo de artritis séptica ${ }^{(9)}$.

\section{Osteomielitis en niños: imágenes y presentación clínica}

La osteomielitis aguda clínicamente se manifiesta por dolor metafisiario, pudiendo ser afebril. En esta etapa los estudios radiográficos y por TC generalmente son normales, observándose sólo en algunos casos sutiles signos como osteopenia local. En la TC se puede observar aumento de la densidad de la médula ósea y/o de las partes blandas y signos de derrame articular en $\mathrm{la}^{(9,10)}$. En el caso expuesto, tanto la radiografía de tórax (Figuras 1 y 2) como la TC con ventana ósea (Figuras 9 y 10), no mostraron alteraciones a nivel esquelético. Es por esto, que la RM es un gran aporte en casos de sospecha de osteomielitis de poco tiempo de evolución (<7 días), observándose cambios inflamatorios, tanto de le médula ósea como de las partes blandas adyacentes en secuencias sensibles al agua (T2 fat-sat y STIR) e impregnación con el medio de contraste paramagnético en los mismo niveles, hallazgos los cuales permitieron hacer el diagnóstico en el caso expuesto (Figuras $12,13,14,15$ y 16$)$.

La etapa sub-aguda (>7-14 días) clínicamente se manifiesta como un síndrome febril prolongado. En los estudios radiográficos y TC se puede hacer evidente reacción perióstica y se establece una lesión lítica (absceso de Brodie), la cual en un principio puede ser poco definida dando más bien un patrón "permeativo" y posteriormente tener bordes escleróticos (Figuras 20a). En la RM se observan hallazgos equivalentes y pueden ser más acentuados los cambios inflamatorios de las partes blandas. Si la enfermedad avanza, con la RM se puede distinguir de mejor manera si hay extensión del absceso a la fisis y epífisis. El exudado purulento también puede extenderse hacia lateral a través de los canales de Havers, alcanzando la superficie cortical y disecando las fibras de Sharpey (que fijan el periostio) formándose abscesos subperiósticos (Figura 20 b), los cuales también son evaluables con la $\mathrm{RM}^{(10,11)}$.

En fase crónica, la irrupción de los vasos superficiales, que irrigan la cortical a través del periostio, determinan isquemia y hueso cortical desvitalizado dando origen al "secuestro". Por otro lado, la gruesa reacción perióstica esclerótica está establecida y forma una neocorteza denominada "involucro" (Figura 20c). Clínicamente esta etapa puede ser oligosintomática y en imágenes es evidente con todas las técnicas anteriormente nombradas, observándose deformidad y engrosamiento cortical, regiones líticas/escleróticas mal definidas y formación de abscesos, tanto intraóseos como subperiósticos y de partes blandas ${ }^{(10,11)}$.
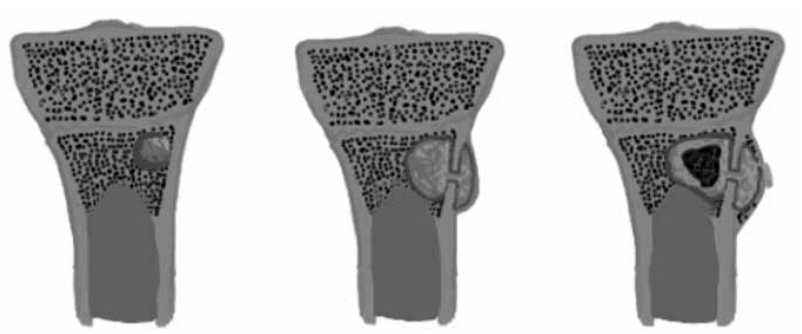

Figuras 20a,b,c. Progresión de osteomielitis: Absceso de Brodie (a), absceso subperióstico (b) y formación de secuestro e involucro (c). 
